\title{
不同生境下濒危植物裸果木种群结构及动态特征
}

\author{
王立龙 ${ }^{1}$ 王 亮 $^{2}$ 张丽芳 ${ }^{1}$ 刘玉洋 ${ }^{1}$ 徐世健 $^{1^{*}}$ \\ 兰州大学生命科学学院, 兰州 $730000{ }^{2}$ 甘肃安西极早荒漠国家级自然保护区管理局, 甘肃酒泉 736100
}

\begin{abstract}
摘 要 裸果木(Gymnocarpos przewalskii)为古地中海早生植物区系子遗种, 是砾质荒漠的主要建群种之一。通过对安西极旱 荒漠国家级自然保护区内3种生境(水冲滩地、山间冲沟、平缓戈壁)条件下裸果木种群的样地调查, 编制不同生境裸果木种群 的静态生命表, 绘制其存活曲线和生存分析函数的曲线, 并采用时间序列模型对种群的数量动态进行预测, 以揭示不同生境 下裸果木的种群结构和动态特征。结果表明: 3 种生境下裸果木种群均属增长型, 数量变化动态指数 $\left(V_{\mathrm{pi}}\right)>0$, 但对外界干扰比 较敏感, 存活曲线趋于Deevey-II型, 表明种群各龄级的死亡率基本接近; 不同生境裸果木种群大小依次为水冲滩地 $>$ 山间冲 沟>平缓戈壁, 结合对种群年龄结构的分析, 进一步表明水分条件较好的水冲滩地和山间冲沟生境更加适宜裸果木生存; 生 存分析和时间序列预测表明幼龄个体的缺乏是未来裸果木种群发生衰退的主要原因，且平缓戈壁生境下的裸果木种群将先 于另外两种生境下的种群发生更加快速的衰退。
\end{abstract}

关键词 裸果木, 生境, 静态生命表, 生存分析, 时间序列预测

引用格式: 王立龙, 王亮, 张丽芳, 刘玉洋, 徐世健 (2015). 不同生境下濒危植物裸果木种群结构及动态特征. 植物生态学报, 39, 980-989. doi: 10.17521/cjpe.2015.0095

\section{Structure and dynamic characteristics of Gymnocarpos przewalskii in different habitats}

\author{
WANG Li-Long ${ }^{1}$, WANG Liang ${ }^{2}$, ZHANG Li-Fang ${ }^{1}$, LIU Yu-Yang ${ }^{1}$, and XU Shi-Jian ${ }^{1 *}$ \\ ${ }^{1}$ School of Life Sciences, Lanzhou University, Lanzhou 730000, China; and ${ }^{2}$ Administration of Anxi Extra-arid Desert National Nature Reserve, Jiuquan, \\ Gansu 736100, China
}

\section{Abstract}

Aims Gymnocarpos przewalskii is a relict plant of the Tethys flora, which is also one of the constructive species in stony desert. Our objective was to determine the structure and dynamic characteristics of G. przewalskii in different habitats.

Methods Based on the equal-area plot investigations in three habitats of G. przewalskii, the static life table was established, survival curves and the function curves derived from the survival analysis were also constructed to evaluate the population characteristics. The population dynamics were predicted by a time-sequence model.

Important findings The survival curves of G. przewalskii appear to approach the Deevey-II type, which indicate that the mortality rate in different size classes was similar, and the population fit in with the growing type in all habitats, but sensitive to environment disturbances. The population size of G. przewalskii was largest in flooding lands, medium in gullies and smallest in the flat desert and the age structure showed that the flooding lands and gullies are better habitats for the growth of $G$. przewalskii. The survival analysis and the time-sequence model demonstrated that the lack of young individuals could be the major cause for population declines of G. przewalskii in all habitats; moreover, a decline is likely to occur in the flat desert earlier and quicker.

Key words Gymnocarpos przewalskii, habitat, life table, survival analysis, time sequence analysis

Citation: Wang LL, Wang L, Zhang LF, Liu YY, Xu SJ (2015). Structure and dynamic characteristics of Gymnocarpos przewalskii in different habitats. Chinese Journal of Plant Ecology, 39, 980-989. doi: 10.17521/cjpe.2015.0095

植物种群的结构特点和时空变化趋势是植物生 态学研究的核心问题之一(Gurevitch et al., 2002)。通 过静态生命表和生存分析展现种群的结构现状和发
展规律(Harcombe, 1987), 同时, 结合种群动态数量 化方法和时间序列分析反映现存种群受干扰情况， 并对其未来的发展趋势进行预测(申仕康等, 2008;

收稿日期Received: 2015-04-21 接受日期Accepted: 2015-09-08

* 通讯作者Author for correspondence (E-mail: xushijian@lzu.edu.cn) 
解婷婷等, 2014), 有利于揭示种群生物学特性与生 境之间的关系, 对濒危物种的保护和管理具有重要 的理论指导意义(吴承祯等, 2000)。

裸果木(Gymnocarpos przewalskii)为石竹科裸 果木属亚灌木状多分枝植物, 属古地中海早生植物 区系成分, 是荒漠区植物中少有的子遗物种, 其演 化发展过程对研究古地中海气候的变化过程具有重 要的科学价值(Ma et al., 2012)。1987年裸果木被定 为国家二级保护植物, 近年来由于过度放牧和土地 开发等人为因素的影响, 其种群数量迅速下降, 分 布范围也不断缩小, 1997年又被确定为国家一级保 护植物(马松梅等, 2010)。目前关于裸果木的生态学 研究主要集中在群落构成和多样性等方面(柴永青 等, 2010; 杨建美等, 2013), 而有关裸果木种群的结 构及动态特征还没有相关报道。本文通过对极旱荒 漠区内3种生境条件下的裸果木种群的调查, 结合种 群静态生命表、时间序列预测以及生存分析, 旨在揭 示裸果木种群的生存现状及动态趋势, 探讨生境与 种群之间的关系, 为裸果木的保护提供科学依据。

\section{1 研究区概况和研究方法}

\section{1 研究区概况}

研究区位于甘肃安西极早荒漠国家级自然保护 区内, 由南北两片组成(南片: $95.85^{\circ}-96.85^{\circ} \mathrm{E}$, $39.85^{\circ}-40.58^{\circ} \mathrm{N}$; 北片: $94.78^{\circ}-95.75^{\circ} \mathrm{E}, 41.32^{\circ}-$ $\left.41.88^{\circ} \mathrm{N}\right)$, 南片地势相对平缓, 缓倾斜洪积扇广布, 而北片地形相对复杂, 低山丘陵广布。保护区平均 海拔 $1800 \mathrm{~m}$, 年平均气温 $8.8{ }^{\circ} \mathrm{C}$, 年降水量 $52 \mathrm{~mm}$, 年蒸发量2 $700 \mathrm{~mm}$, 属典型的温带沙漠气候类型。 该区自然植被稀疏, 植物群落主要由旱生植物组成, 主要包括合头草(Sympegma regelii)、膜果麻黄 (Ephedra przewalskii)、红砂(Reaumuria soongarica)、 珍珠猪毛菜(Salsola passerina)、泡泡刺 (Nitraria sphaerocarpa)、裸果木等。

\section{2 研究方法}

\subsection{1 样地设置及调查方法}

2014年8-9月, 在全面调查安西极早荒漠自然 保护区裸果木分布状况的基础上, 确定裸果木的3 种典型的生境: 水冲滩地, 包括滩涂地和缓冲积扇 在内的易受洪水影响的易积水区域; 山间冲沟, 包 括山峰之间以及丘陵之间的易受雨水和山洪影响的 区域; 平缓戈壁, 主要指除滩涂地和冲积扇以外无
明显水冲条带的平缓区域。在每种生境中具有代表 性的裸果木分布地段设置一块 $3600 \mathrm{~m}^{2}$ 的样地, 每 一样地划分为 36 个 $10 \mathrm{~m} \times 10 \mathrm{~m}$ 的样方, 记录样方内 每种灌木的个体数、高度、冠幅以及盖度等指标。

\subsection{2 年龄结构的建立}

对于木本植物尤其是濒危物种年龄结构的划 分, 大多数学者采用径级结构或者高度级结构代替 时间顺序关系(王巍等, 1999; 申仕康等, 2008)。裸果 木为半椭球型亚灌木状植物, 地上多分枝, 无明显 主干，因而无法采用径级代其替年龄结构。虽然种 群的龄级和高度、冠幅等有所不同，但在不受人类 和其他动物干扰的同一环境下，难以用径级反映年 龄的同一树种的龄级和高度级对环境的反应规律在 一定范围内应该具有一致性。同时, 由于裸果木植 株高度和冠幅之间呈现较好且相近的线性正相关关 系(本次调查数据: 水冲滩地: $R^{2}=0.73, p<0.001, n$ = 382; 山间冲沟: $R^{2}=0.75, p<0.001, n=147$; 平 缓戈壁: $\left.R^{2}=0.65, p<0.001, n=133\right)$ 。结合本次调查 实际情况, 本文采用裸果木高度级结构代替年龄结 构来分析种群的年龄结构及其动态特征, 将裸果木 植株高度 $(H)$ 的分布状况划分为 10 个龄级：I级 $(H<$ $10 \mathrm{~cm}) 、 \mathrm{II}$ 级 $(10 \mathrm{~cm} \leqslant H<20 \mathrm{~cm}) \ldots \ldots$, 以 $10 \mathrm{~cm}$ 为 间隔, 共 10 个等级; 分别统计不同生境下各龄级植 株的个体数, 编制裸果木种群的静态生命表。

\subsection{3 种群动态量化方法}

为了定量描述不同生境下裸果木的种群动态, 参考陈晓德(1999)植物种群与群落结构动态量化分 析方法:

$$
\begin{aligned}
& V_{n}=\frac{S_{n}-S_{n+1}}{\max \left(S_{n}, S_{n+1}\right)} \times 100 \% \\
& V_{p i}=\frac{1}{\sum_{n=1}^{k-1} S_{n}} \sum_{n=1}^{k-1}\left(S_{n} V_{n}\right)
\end{aligned}
$$

式(1)中, $V_{n}$ 为种群内各龄级间个体数量的变化动态; 式(2)中 $V_{p i}$ 为整个种群的数量变化动态(忽略外部干 扰); 而当考虑未来的外部干扰时, $V_{p i}$ 还与年龄级数 量 $(k)$ 以及各龄级内的个体数 $\left(S_{n}\right)$ 相关, 可进一步将 式(2)修正为:

$$
V_{p i}^{\prime}=\frac{\sum_{n=1}^{k-1} S_{n} V_{n}}{\min \left(S_{1}, S_{2}, S_{3}, \cdots, S_{k}\right) k \sum_{n=1}^{k-1} S_{n}}
$$




$$
P_{\text {极大 }}=\frac{1}{K \min \left(S_{1}, S_{2}, S_{3}, \cdots, S_{k}\right)}
$$

式中, $V_{n} 、 V_{p i} 、 V_{p i}^{\prime}$ 取正、负、0值时分别反映种群个 体数量的增长、衰退和稳定的结构动态关系。仅当 $P$ (种群对外界干扰所承担的风险概率) 取值为最大 时才会对种群动态 $V_{p i}^{\prime}$ 构成最大的影响。

\subsection{4 种群静态生命表和存活曲线的编绘}

静态生命表也称特定时间生命表, 编制过程需 要满足3个理想化的假设: (1)种群密度不变, 即种群 是静态的; (2)种群具有稳定的年龄结构且其变化与 时间无关; (3)种群内个体的迁入迁出数量相等。而 实际调查过程中, 裸果木的自然种群中多世代重叠, 因而调查数据不能完全满足静态生命表的 3 个假设, 故采用匀滑技术(江洪等, 1992)对数据进行处理。生 命表的各项均相互关联, 可以通过野外调查获得不 同生境下裸果木种群各龄级的个体数计算得到, 具 体编制方法参考吴承祯等(2000)。

为了检验种群存活状况是符合Deevey-II型还 是Deevey-III型曲线, 本文采用Hett和Loucks提出的 数学模型对不同生境下裸果木种群存活曲线进行检 验。即用指数方程 $N_{x}=N_{0} \mathrm{e}^{-b x}$ 和幂函数方程 $N_{x}=$ $N_{0} x^{-b}$ 分别描述 Deevey-II 、 Deevey-III型存活曲线 (Hett \& Loucks, 1976)。式中 $N_{x} 、 N_{0}$ 分别代表 $x$ 龄级 内存活数和种群形成初期的个体数, $b$ 为死亡率。

\subsection{5 生存分析方法}

为了更好地揭示裸果木种群的动态变化规律, 本文引入生存分析中的种群生存率函数 $S_{x}$ 、种群累 计死亡率函数 $F_{x}$ 、种群死亡密度函数 $f_{x}$ 以及种群危险 率函数 $\lambda_{x}$, 参考杨风翔等(1991)的公式进行计算。

\subsection{6 时间序列预测}

本研究采用时间序列分析中的一次移动平均 法(肖宜安等, 2004)对裸果木种群年龄结构进行 预测。

$$
M_{t}^{(1)}=\frac{1}{n} \sum_{k=t-n+1}^{t} X_{k}
$$

式中, $n$ 为需要预测的时间(本文为龄级时间), (1)表 示 1 次移动平均, $t$ 代表龄级, $X_{k}$ 为 $k$ 龄级内的个体数 量, $M_{\mathrm{t}}{ }^{(1)}$ 表示经过未来 $n$ 个龄级时间后 $t$ 龄级的种群 大小。本文对经过2、4、6、8龄级时间后的裸果木 种群各龄级的个体数量进行预测。

\section{2 结果和分析}

\section{1 不同生境下植物群落特征}

不同生境下样地的植被调查结果表明: 合头草 是研究区的主要建群种, 其在3种生境下的重要值 排名均在前3位, 泡泡刺在山间冲沟和水冲滩地生 境内也是排名前3位的主要建群种(表1)。而裸果木 在水冲滩地、山间冲沟以及平缓戈壁中的排名呈现 降低的趋势, 分别为第2、3、5位, 由建群种逐渐变 为伴生种; 与此不同的是, 红砂则由水冲滩地和山 间冲沟中的伴生种(均排第4位)成为平缓戈壁生境 中排名第1的主要建群种(表1)。

\section{2 裸果木种群分布现状及结构特征}

在所调查的对象中, 各龄级裸果木在水冲滩地 样地内有 382 株, 山间冲沟样地为 147 株, 平缓戈壁 样地为 133 株。以龄级为横坐标, 各龄级内个体所占 百分比为纵坐标, 绘制不同生境下裸果木种群的龄 级结构图(图1)。结果显示, 3种生境下裸果木种群大 小级结构均呈中部彭大的非典型的金字塔型, 其中 水冲滩地和平缓戈壁内 $\mathrm{IV}$ 龄级裸果木所占比例最 多分别为 $18.6 \%$ 和 $26.3 \%$, 山间冲沟内 $\mathrm{V}$ 龄级裸果木 所占比例最高为 $20.3 \%$ 。所有生境下个体数量从 $\mathrm{V}$ 龄 级开始减少, VII龄级后急剧降低。总体来看, 3 种生 境下幼龄裸果木个体数量均较少, 且在平缓戈壁内 I、II龄级个体分别仅占整个种群的 $1.5 \%$ 和 $3.8 \%$ 。

通过种群动态量化方法对不同生境下裸果木种 群相邻大小级的变化动态进行分析, 结果显示, 水 冲滩地和平缓戈壁生境下裸果木种群相邻各级间个 体数量变化动态指数 $V_{1} 、 V_{2} 、 V_{3}$ 均小于 0 , 说明 $\mathrm{I} 、 \mathrm{II}$ 、 III龄级个体数目少于IV龄级个体数目, 呈现衰退的 结构动态关系, $\mathrm{IV}$ 龄级之后相邻龄级则呈现增长的 结构动态关系。在山间冲沟生境下, 动态量值 $V_{1}$ 、 $V_{3} 、 V_{4}$ 均小于 0 , 而 $V_{2}$ 大于 0 , 呈现“衰退-增长-衰退” 的波动的结构动态关系(表2)。进一步计算不同生境 下裸果木种群的总体数量动态变化指数 $V_{p i}$ (不考虑 外界干扰)和 $V_{p i}^{\prime}$ (受外界随机干扰), 结果显示, 3 种 生境下裸果木种的总体数量动态变化指数 $V_{p i}^{\prime}$ 均小 于 $V_{p i}$ 但都大于 0 , 其中 $V_{p i}^{\prime}$ 更加趋于 0 (表2), 随机干 扰风险极大值 $\left(P_{\text {极大 }}\right.$ ) 分别为 0.03 (水冲滩地生境)、 0.1 (山间冲沟生境)、 0.1 (平缓戈壁生境), 说明 3 种生境 下裸果木种群总体均表现为增长型, 但增长缓慢, 对外界干扰具有较高的敏感性。 
表1 不同生境下植物群落组成及其数量特征

Table 1 Community composition and quantity characteristics in different habitats

\begin{tabular}{|c|c|c|c|c|c|c|c|}
\hline $\begin{array}{l}\text { 生境 } \\
\text { Habitat }\end{array}$ & $\begin{array}{l}\text { 物种名称 } \\
\text { Species name }\end{array}$ & $\begin{array}{c}\text { 平均密度 } \\
\text { Mean density } \\
\text { (plants·plot }^{-1} \text { ) }\end{array}$ & $\begin{array}{c}\text { 平均高度 } \\
\text { Mean } \\
\text { height (m) }\end{array}$ & $\begin{array}{c}\text { 平均冠幅 } \\
\text { Mean crown } \\
\text { (m) }\end{array}$ & $\begin{array}{c}\text { 平均盖度 } \\
\text { Mean canopy } \\
\text { (\%) }\end{array}$ & $\begin{array}{l}\text { 重要值 } \\
\text { Important } \\
\text { value }\end{array}$ & $\begin{array}{l}\text { 群落组成 } \\
\text { Community } \\
\text { composition }\end{array}$ \\
\hline \multirow{5}{*}{$\begin{array}{l}\text { 水冲滩地 } \\
\text { Flooding land } \\
\text { (20) }\end{array}$} & 1. 膜果麻黄 Ephedra przewalskii & 11.02 & 0.29 & 1.06 & 3.20 & 0.13 & \multirow{5}{*}{$\begin{array}{l}\text { 膜 果 麻 黄 } E . \text {. } \\
\text { przewalskii }+ \text { 裸果 } \\
\text { G. przewalskii }+ \text { 合头 } \\
\text { 草 S.regelii }\end{array}$} \\
\hline & 2. 裸果木 Gymnocarpos przewalskii & 10.60 & 0.34 & 0.74 & 3.10 & 0.12 & \\
\hline & 3. 合头草 Sympegma regelii & 7.31 & 0.42 & 0.78 & 2.23 & 0.10 & \\
\hline & 4. 红砂 Reaumuria songarica & 4.17 & 0.38 & 0.80 & 1.26 & 0.07 & \\
\hline & 5. 细枝岩黄芪 Hedysarum scoparium & 1.61 & 0.62 & 1.18 & 0.66 & 0.06 & \\
\hline \multirow{5}{*}{$\begin{array}{l}\text { 山间冲沟 } \\
\text { Gully } \\
\text { (18) }\end{array}$} & 1. 合头草 Sympegma regelii & 13.80 & 0.43 & 0.80 & 3.00 & 0.19 & \multirow{5}{*}{$\begin{array}{l}\text { 合头草 } S . \text { regelii + 泡 } \\
\text { 泡刺 N. sphaerocarpa } \\
+\quad \text { 裸 果 木 } \\
\text { przewalskii }\end{array}$} \\
\hline & 2. 泡泡刺 Nitraria sphaerocarpa & 4.00 & 0.29 & 1.35 & 3.20 & 0.13 & \\
\hline & 3. 裸果木 Gymnocarpos przewalskii & 4.10 & 0.36 & 0.85 & 3.00 & 0.12 & \\
\hline & 4. 红砂 Reaumuria songarica & 2.80 & 0.27 & 0.68 & 0.80 & 0.06 & \\
\hline & 5. 沙拐杳 Calligonum mongolicum & 0.41 & 0.56 & 1.17 & 0.42 & 0.05 & \\
\hline \multirow{5}{*}{$\begin{array}{l}\text { 平缓戈壁 } \\
\text { Flat desert } \\
\text { (18) }\end{array}$} & 1. 红砂 Reaumuria songarica & 11.80 & 0.26 & 0.75 & 2.20 & 0.14 & \multirow{5}{*}{$\begin{array}{l}\text { 红砂 R. songarica }+ \text { 泡 } \\
\text { 泡刺 N. sphaerocarpa } \\
+ \text { 合头草 S. regelii }\end{array}$} \\
\hline & 2. 泡泡刺 Nitraria sphaerocarpa & 7.02 & 0.27 & 0.91 & 1.81 & 0.11 & \\
\hline & 3. 合头草 Sympegma regelii & 6.68 & 0.39 & 0.60 & 1.80 & 0.10 & \\
\hline & 4. 膜果麻黄 Ephedra przewalskii & 2.91 & 0.37 & 0.95 & 1.92 & 0.09 & \\
\hline & 5. 裸果木 Gymnocarpos przewalskii & 2.64 & 0.42 & 0.81 & 1.85 & 0.09 & \\
\hline
\end{tabular}

平均密度、高度、冠幅、盖度为每种生境内样方的平均值; 群落中排名前5位的物种以其重要值 $(I V)$ 降序排列; $I V=($ 相对密度 + 相对高度+相对冠幅+相 对盖度)/4; 群落组成以每种生境下重要值排名前三的物种表示; 括号中的数字表示每种生境内植物物种的数量。

Mean density, mean height, mean crown spread, mean canopy cover are the average values of all the plots in each habitat; the descending order of the top five species in the community was based on the important value $(I V)$; $I V=$ (Mean density + Mean height + Mean crown + Mean canopy)/4; the community composition was represented by the top three species based on $I V$; the numbers in the parentheses represent the number of species in each habitat.

表2 不同生境下裸果木种群龄级结构动态变化指数

Table 2 Dynamic indices of Gymnocarpos przewalskii population and size structure in different habitats

\begin{tabular}{|c|c|c|c|}
\hline \multirow{2}{*}{$\begin{array}{l}\text { 种群动态指数级 } \\
\text { Dynamic index }\end{array}$} & \multicolumn{3}{|c|}{ 动态指数 Dynamic index value (\%) } \\
\hline & $\begin{array}{c}\text { 水冲滩地 } \\
\text { Flooding land }\end{array}$ & $\begin{array}{c}\text { 山间冲沟 } \\
\text { Gully }\end{array}$ & $\begin{array}{l}\text { 平缓戈壁 } \\
\text { Flat desert }\end{array}$ \\
\hline$V_{1}$ & -26.67 & -40.74 & -60.00 \\
\hline$V_{2}$ & -10.45 & 40.74 & -77.27 \\
\hline$V_{3}$ & -5.63 & -23.81 & -37.14 \\
\hline$V_{4}$ & 11.27 & -30.00 & 20.00 \\
\hline$V_{5}$ & 31.75 & 46.67 & 0.00 \\
\hline$V_{6}$ & 60.47 & 31.25 & 71.43 \\
\hline$V_{7}$ & 35.29 & 36.36 & 75.00 \\
\hline$V_{8}$ & 72.73 & 85.71 & 0.00 \\
\hline$V_{9}$ & 66.67 & -66.67 & 50.00 \\
\hline$V_{p i}$ & 12.72 & 15.66 & 15.73 \\
\hline$V_{p i}^{\prime}$ & 1.27 & 1.57 & 1.57 \\
\hline
\end{tabular}

\section{3 裸果木种群静态生命表及存活曲线}

生命表分析结果显示，随着裸果木年龄的增加， 存活数 $\left(l_{\mathrm{x}}\right)$ 逐渐减少, 个体的期望寿命 $\left(e_{\mathrm{x}}\right)$ 在 $\mathrm{I} 、 \mathrm{II}$ 级后 逐渐降低。3种生境下裸果木种群均呈现一定的波动 性, 总体表现为 I、II级的个体数较少, 即缺乏幼年阶 段的个体, 在IV、V 级时达到种群个体数量的高峰
(表3)。由不同生境下裸果木种群的存活曲线(图2) 可以看出, 水冲滩地和山间冲沟两种生境下裸果木 种群的存活曲线变化趋势比较接近, I至 $V$ 级成活率 下降均较平缓戈壁生境更加平缓, V至VIII级的下降 趋势在3种生境中基本一致, VIII龄级之后下降趋势 加快。相应的幕函数和指数模型比较分析表明, 两 种模型的拟合结果在不同生境下均达到显著水平, 但指数模型的 $R^{2}$ 值在不同生境下均大于幂函数模 型，且 $p$ 值更小 (表4), 因此认为3种生境下裸果木种 群存活曲线更加符合Deevey-II型。由死亡率和消失 率曲线(图3)可以看出, 山间冲沟生境下裸果木种群 的死亡率和消失率随年龄的增加而升高, 无波动; 而在水冲滩地和平缓戈壁生境下裸果木种群的死亡 率和消失率均发生不同程度的波动, 且在平缓戈壁 生境下IV龄级之后尤为频繁，反映出不同生境下的 环境选择压力对裸果木种群死亡率和消失率有着不 同的影响。

\section{4 裸果木种群的生存分析}

根据生存分析的结果, 绘制不同生境下裸果木 种群的生存率 $\left(S_{\mathrm{x}}\right)$ 和累计死亡率 $\left(F_{\mathrm{x}}\right)$ 曲线(图4)以及 死亡密度 $\left(f_{\mathrm{x}}\right)$ 和危险率 $\left(\lambda_{\mathrm{x}}\right)$ 曲线(图5)。由图4可以看 

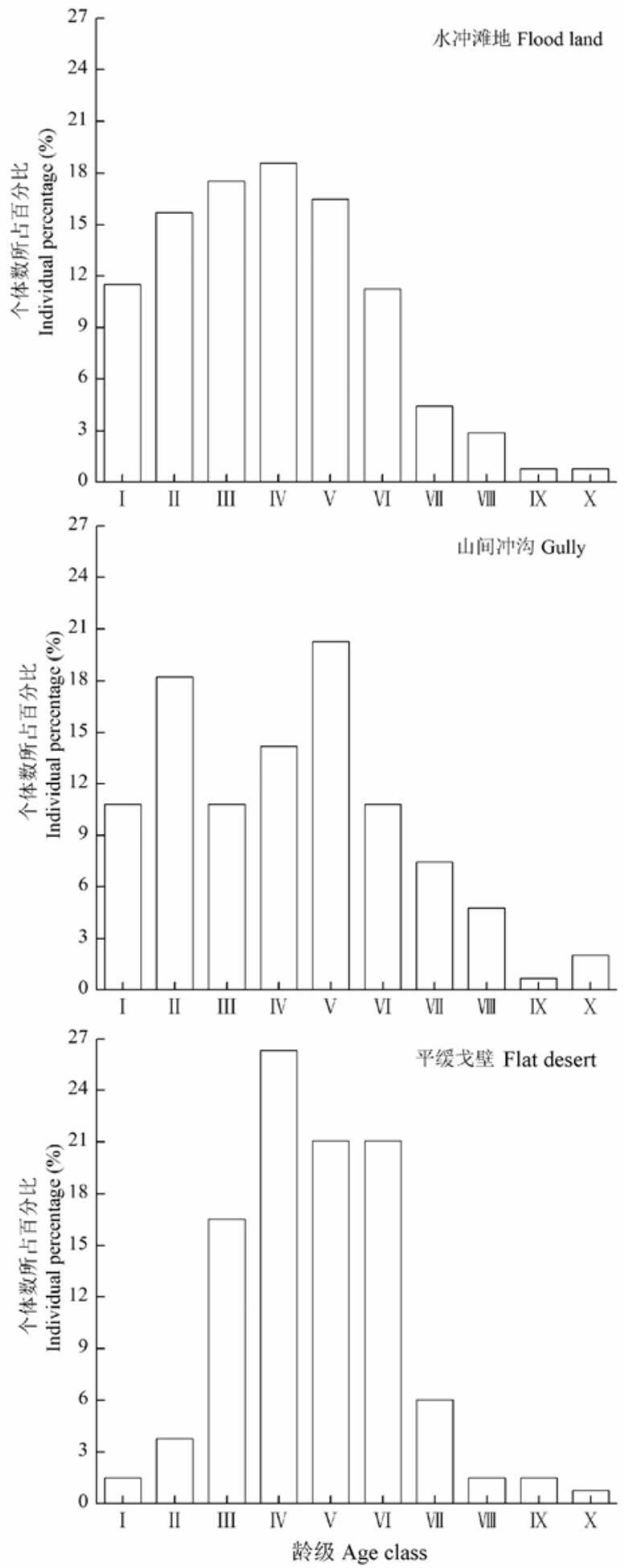

图1 不同生境下裸果木种群的龄级结构。采用高度级 $(H)$ 结构代替年龄结构, 以 $10 \mathrm{~cm}$ 为间隔共划分 10 个龄级, I $(H$ $<10 \mathrm{~cm}) 、$ II $(10 \mathrm{~cm} \leqslant H<20 \mathrm{~cm}) \ldots . . \mathrm{X}(\mathrm{H} \geqslant 100 \mathrm{~cm})$ 。

Fig. 1 The age structure of Gymnocarpos przewalskii population in different habitats. The age structure was replaced by height-class structure $(H)$, totally 10 age classes were divided in intervals of $10 \mathrm{~cm}$, I $(H<10 \mathrm{~cm})$, II $(10 \mathrm{~cm} \leqslant H<20 \mathrm{~cm}) \ldots$, $\mathrm{X}(H \geqslant 100 \mathrm{~cm})$.

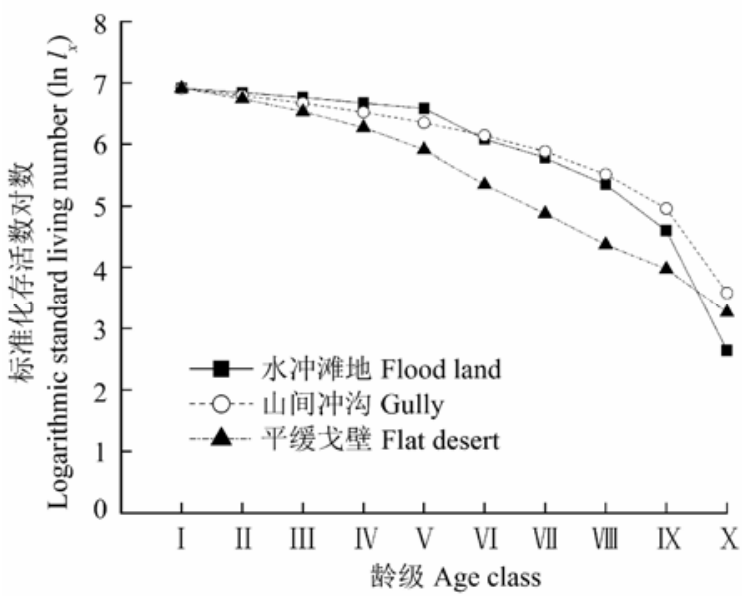

图2 不同生境下裸果木种群的存活曲线。龄级同图1。

Fig. 2 Survival curve of Gymnocarpos przewalskii population in different habitats. Age class see Fig. 1.

出, 生存率和累计死亡率二者互补, 随着龄级的增 加, 3种生境下裸果木种群的生存率逐渐下降, 而累 积死亡率逐渐上升。在 4.5 龄级处，水冲滩地和山间 冲沟生境中的裸果木种群的生存率和累积死亡率均 达到平衡，说明4.5龄级之后种群开始逐渐向衰退的 方向发展(图4)。与此不同的是，平缓戈壁生境中的 裸果木种群的生存率和死亡率约在3.2龄级时达到 平衡(图4), 这反映出此生境中的裸果木种群较另外 两种生境更早进入衰退期。

由图5可以看出, 不同生境下裸果木种群的死 亡密度和危险率曲线反差明显，但在3种生境下的 变化趋势基本一致, 在 $\mathrm{X}$ 龄级达到最大值均为且均 为 0.20 左右。虽然随着年龄的增加, 裸果木死亡率在 增加, 但是相对于危险率曲线, 裸果木种群的死亡 密度曲线走势基本稳定，基本保持在 0.30 以下，这 主要是因为随着年龄的增加, 老龄的裸果木个体数 量也在减少。结合生境特点, 死亡密度曲线在山间 冲沟和平缓戈壁生境下的变化基本持平，保持在0.2 以下，而在水冲滩地生境下呈现出轻微的波动，且 在IV龄级处达到峰值(图5)。因此, 不同生境下的环 境压力对裸果木种群的影响虽然不同，但都主要集 中在 $\mathrm{V}$ 龄级之前, 即裸果木种群发展的前期和中期。

\section{5 裸果木种群数量的时间序列分析}

基于不同生境下裸果木种群中各龄级个体数, 对未来 $2 、 4 、 6 、 8$ 龄级时间后各龄级内的个体数量 进行预测(表5)。结果显示, 在经历未来2、4、6、8 龄级的时间之后, 3 种生境下裸果木种群从VI龄级 
表3＼cjkstart不同生境下裸果木种群静态生命表

Table 3 Static life table of Gymnocarpos przewalskii population in different habitats

\begin{tabular}{|c|c|c|c|c|c|c|c|c|c|c|c|c|}
\hline $\begin{array}{l}\text { 生境 } \\
\text { Habitat }\end{array}$ & $\begin{array}{l}\text { 龄级 } \\
\text { Age class }\end{array}$ & $\begin{array}{l}\text { 高度 } \\
\text { Height (cm) }\end{array}$ & $\overline{A_{x}}$ & $a_{x}$ & $l_{x}$ & $d_{x}$ & $q_{x}$ & $\bar{L} L_{x}$ & $\overline{T_{x}}$ & $\overline{e_{x}}$ & $\ln l_{x}$ & $K_{x}$ \\
\hline \multirow{10}{*}{$\begin{array}{l}\text { 水冲滩地 } \\
\text { Flooding land }\end{array}$} & I & $H<10$ & 44 & 71 & 1000 & 70 & 0.07 & 965 & 4876 & 4.88 & 6.91 & 0.07 \\
\hline & II & $10 \leqslant H<20$ & 60 & 66 & 930 & 71 & 0.08 & 895 & 3911 & 4.21 & 6.84 & 0.08 \\
\hline & III & $20 \leqslant H<30$ & 67 & 61 & 859 & 70 & 0.08 & 824 & 3016 & 3.51 & 6.76 & 0.09 \\
\hline & IV & $30 \leqslant H<40$ & 71 & 56 & 789 & 71 & 0.09 & 753 & 2192 & 2.78 & 6.67 & 0.09 \\
\hline & V & $40 \leqslant H<50$ & 63 & 51 & 718 & 281 & 0.39 & 578 & 1439 & 2.00 & 6.58 & 0.50 \\
\hline & VI & $50 \leqslant H<60$ & 43 & 31 & 437 & 113 & 0.26 & 381 & 861 & 1.97 & 6.08 & 0.30 \\
\hline & VII & $60 \leqslant H<70$ & 17 & 23 & 324 & 113 & 0.35 & 268 & 480 & 1.48 & 5.78 & 0.43 \\
\hline & VIII & $80 \leqslant H<90$ & 11 & 15 & 211 & 112 & 0.53 & 155 & 212 & 1.00 & 5.35 & 0.75 \\
\hline & IX & $90 \leqslant H<100$ & 3 & 7 & 99 & 85 & 0.86 & 57 & 57 & 0.58 & 4.60 & 1.96 \\
\hline & $\mathrm{X}$ & $H \geqslant 100$ & 3 & 1 & 14 & - & - & - & - & - & 2.64 & - \\
\hline \multirow{10}{*}{$\begin{array}{l}\text { 山间冲沟 } \\
\text { Gully }\end{array}$} & I & $H<10$ & 16 & 28 & 1000 & 107 & 0.11 & 946 & 4661 & 4.66 & 6.91 & 0.12 \\
\hline & II & $10 \leqslant H<20$ & 27 & 25 & 893 & 107 & 0.12 & 839 & 3714 & 4.16 & 6.79 & 0.12 \\
\hline & III & $20 \leqslant H<30$ & 16 & 22 & 786 & 107 & 0.14 & 732 & 2875 & 3.66 & 6.67 & 0.15 \\
\hline & IV & $30 \leqslant H<40$ & 21 & 19 & 679 & 108 & 0.16 & 625 & 2143 & 3.16 & 6.52 & 0.17 \\
\hline & $\mathrm{V}$ & $40 \leqslant H<50$ & 30 & 16 & 571 & 107 & 0.19 & 518 & 1518 & 2.66 & 6.35 & 0.21 \\
\hline & VI & $50 \leqslant H<60$ & 16 & 13 & 464 & 107 & 0.23 & 411 & 1000 & 2.15 & 6.14 & 0.26 \\
\hline & VII & $60 \leqslant H<70$ & 11 & 10 & 357 & 107 & 0.30 & 304 & 589 & 1.65 & 5.88 & 0.36 \\
\hline & VIII & $80 \leqslant H<90$ & 7 & 7 & 250 & 107 & 0.43 & 196 & 286 & 1.14 & 5.52 & 0.56 \\
\hline & IX & $90 \leqslant H<100$ & 0 & 4 & 143 & 107 & 0.75 & 89 & 89 & 0.63 & 4.96 & 1.38 \\
\hline & $\mathrm{X}$ & $H \geqslant 100$ & 3 & 1 & 36 & - & - & - & - & - & 3.58 & - \\
\hline \multirow{10}{*}{$\begin{array}{l}\text { 平缓戈壁 } \\
\text { Flat desert }\end{array}$} & I & $H<10$ & 2 & 38 & 1000 & 158 & 0.16 & 921 & 3408 & 3.41 & 6.91 & 0.17 \\
\hline & II & $10 \leqslant H<20$ & 5 & 32 & 842 & 158 & 0.19 & 763 & 2487 & 2.95 & 6.74 & 0.21 \\
\hline & III & $20 \leqslant H<30$ & 22 & 26 & 684 & 158 & 0.23 & 605 & 1724 & 2.52 & 6.53 & 0.26 \\
\hline & IV & $30 \leqslant H<40$ & 35 & 20 & 526 & 158 & 0.30 & 447 & 1118 & 2.13 & 6.27 & 0.36 \\
\hline & $\mathrm{V}$ & $40 \leqslant H<50$ & 28 & 14 & 368 & 157 & 0.43 & 289 & 671 & 1.82 & 5.91 & 0.56 \\
\hline & VI & $50 \leqslant H<60$ & 28 & 8 & 211 & 79 & 0.38 & 171 & 382 & 1.81 & 5.35 & 0.47 \\
\hline & VII & $60 \leqslant H<70$ & 8 & 5 & 132 & 53 & 0.40 & 105 & 211 & 1.60 & 4.88 & 0.51 \\
\hline & VIII & $80 \leqslant H<90$ & 2 & 3 & 79 & 26 & 0.33 & 66 & 105 & 1.33 & 4.37 & 0.40 \\
\hline & IX & $90 \leqslant H<100$ & 2 & 2 & 53 & 27 & 0.51 & 39 & 39 & 0.75 & 3.97 & 0.71 \\
\hline & $\mathrm{X}$ & $H \geqslant 100$ & 1 & 1 & 26 & - & - & - & - & - & 3.26 & - \\
\hline
\end{tabular}

$A_{x}, x$ 龄级内存活个体数; $a_{x}$, 匀滑修正后 $x$ 龄级内的存活个体数; $l_{x}, x$ 龄级开始时的标准化存活个体数 (一般校正为 1000 ); $\ln l_{r}, l \mathrm{x}$ 的自然对数; $d_{x}, x$ 龄级到 $x+1$ 龄级间的标准化死亡数; $q_{x}, x$ 龄级到 $x+1$ 龄级间的死亡率; $L_{x}, x$ 龄级到 $x+1$ 龄级间平均存活个体数; $T_{x}, x$ 龄级到超过 $x$ 龄级的个体总数; $e_{x}$, 进入 $x$ 龄 级个体的期望寿命; $K_{x}$, 各龄级内的消失率。破折号 $(-)$ 表示由于X为最后一个龄级而无法计算的数据。龄级同图 1 。

$A_{x}$, survival number of age $x ; a_{x}$, correction value of survival number of age $x ; l_{x}$, standardized number of survivors at the beginning of age $x$; $\ln l_{x}$, natural logarithm of $l_{x} ; d_{x}$, standardized number of mortality from age $x$ to $x+1 ; q_{x}$, mortality from age $x$ to $x+1 ; L_{x}$, number of survivors from age $x$ to $x+1 ; T_{x}$, total individual number of age $x$ and beyond; $e_{x}$, life expectation of individual in age $x$ class; $K_{x}$, elimination rate. Dashes $(-)$ represent the incalculable data because $\mathrm{X}$ is the last age class. Age class see Fig. 1.

之后的个体数均呈现增加的趋势(表5)。而在种群发 展的前、中期, 各龄级个体数量的时间序列预测总 体呈减少的趋势, 其中IV龄级的个体数量经历 $2 、 4$ 龄级时间之后分别下降了 $14.1 \%$ (水冲滩地)、 $5 \%$ (山 间冲沟)、 $54.3 \%$ (平缓戈壁), 说明3种生境下的裸果 木种群均不同程度地缺乏幼龄个体。综上所述, 从 裸果木种群的整个发展阶段来看, 虽然目前中老龄 阶段的个体数能够在现有的基础上得到补充, 但是
由于幼龄植株的缺乏, 种群更新将难以维持, 所以 3 种生境下的裸果木种群未来仍然会不同程度地趋于 衰退。

\section{3 讨论}

\section{1 不同生境下裸果木种群的结构与适宜性}

植物种群作为物种存在的基本单位，其结构特 征是植物对外界环境适应性的集中体现(Gurevitch 
表4 不同生境下裸果木种群存活曲线的检验模型

Table 4 Test models of survival curves of Gymnocarpos przewalskii in different habitats

\begin{tabular}{lllll}
\hline 生境 Habitat & 方程 Equation & $R^{2}$ & $F$ & $p$ \\
\hline 水冲滩地 & $N_{\mathrm{x}}=8.718 \mathrm{e}^{-0.079 x}$ & 0.660 & 15.52 & 0.004 \\
Flooding land & $N_{\mathrm{x}}=8.409 x^{-0.266}$ & 0.432 & 6.076 & 0.039 \\
山间冲沟 & $N_{\mathrm{x}}=7.986 \mathrm{e}^{-0.057 \mathrm{x}}$ & 0.745 & 23.42 & 0.001 \\
Gully & $N_{\mathrm{x}}=7.858 x^{-0.197}$ & 0.521 & 8.711 & 0.018 \\
平缓戈壁 & $N_{\mathrm{x}}=8.223 \mathrm{e}^{-0.081 \mathrm{x}}$ & 0.935 & 115.6 & 0.000 \\
Flat desert & $N_{\mathrm{x}}=8.216 x^{-0.294}$ & 0.724 & 21.02 & 0.002 \\
\hline
\end{tabular}

et al., 2002)。比较不同生境下的裸果木种群特征有 助于了解这一古老的子遗物种与其生存环境之间的 适合度。调查结果显示, 研究区裸果木种群的年龄 结构均呈基部狭窄的非典型金字塔型。从种群大小 来看, 3种生境下裸果木种群的个体数量分别为水冲 滩地>山间冲沟>平缓戈壁。从年龄结构来看, 不同 生境下的裸果木种群均呈现幼龄个体缺乏的特点, 其中I、II龄级个体在水冲滩地和山间冲沟生境中所 占比例接近, 均远高于在平缓戈壁生境中所占比 例。幼龄个体的数量是维持种群稳定性的基础(易雪 梅等, 2013; 解婷婷等, 2014), 对于许多濒危物种来 说更是如此(谢宗强等, 1999; 洪伟等, 2004)。因此, 裸果木更适宜生长在水分条件相对更好的水冲滩地 和山间冲沟生境内, 且在这两种生境中可作为建群 种存在, 从而维持其种群在群落中的稳定性。而红 砂作为典型的超旱生植物, 其在平缓戈壁生境中的 绝对优势地位也进一步反映出生境水分条件的恶 化。综合来看, 与合头草、膜果麻黄、泡泡刺等研 究区常见的广布建群种不同, 裸果木对生境水分条 件的要求更高。

分子谱系研究表明: 裸果木的种群数量和分布 范围的迅速扩张发生在新生代早期, 当时的河西走 廊地区古气候温暖湿润, 疏勒河流域在这一时期曾 沼泽遍布(郑国璋等, 2006), 直到新生代中晚期阶段, 逐渐形成的荒漠化气候才限制了其种群的进一步扩 展(Ma \& Zhang, 2012)。因此, 裸果木作为子遗物种在 古气候条件下就与其生境的水分条件关系密切。经历 漫长的旱化演化过程后, 虽然裸果木能够适应极端干 旱的环境, 但其自身对生境中水分条件的较高的依赖 性在一定程度上导致其与现在的极旱荒漠化生境之 间的适合度范围变得更窄(马松梅等, 2010)。

\section{2 不同生境下裸果木种群的发展趋势}

存活曲线一般分为 3 种类型, 其中I型是凸曲线,
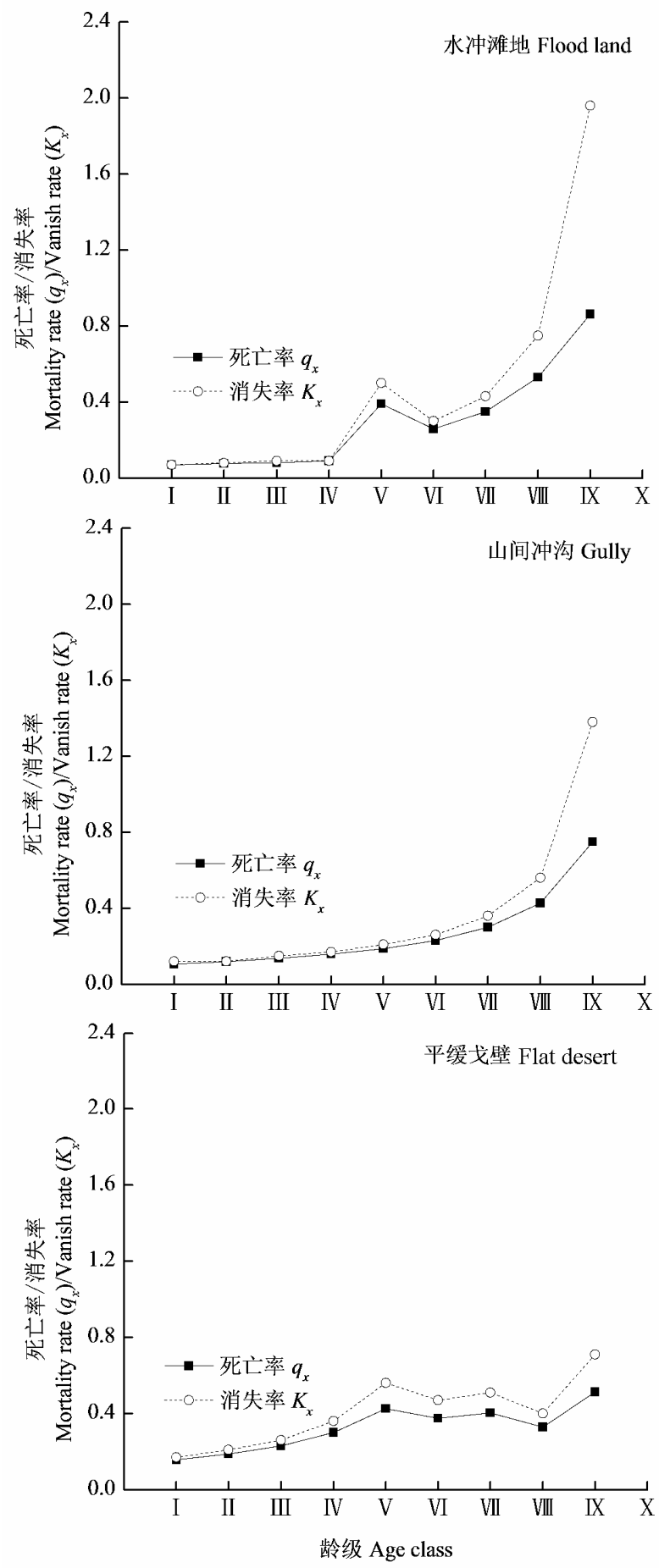

图3 不同生境下裸果木种群的死亡率和消失率。龄级同图1。 Fig. 3 Mortality rate and disappearance rate of Gymnocarpos przewalskii population in different habitats. Age class see Fig. 1.

幼龄个体存活率较高, 当达到一定的年龄时死亡率 会快速增加; II型接近似于直线, 各龄级内死亡率相 近, 种群相对稳定; III为凹型曲线, 幼龄个体具有 较高死亡率，但随着年龄的增加逐渐降低(Deevey, 1947)。本研究表明, 不同生境下裸果木种群的存活 

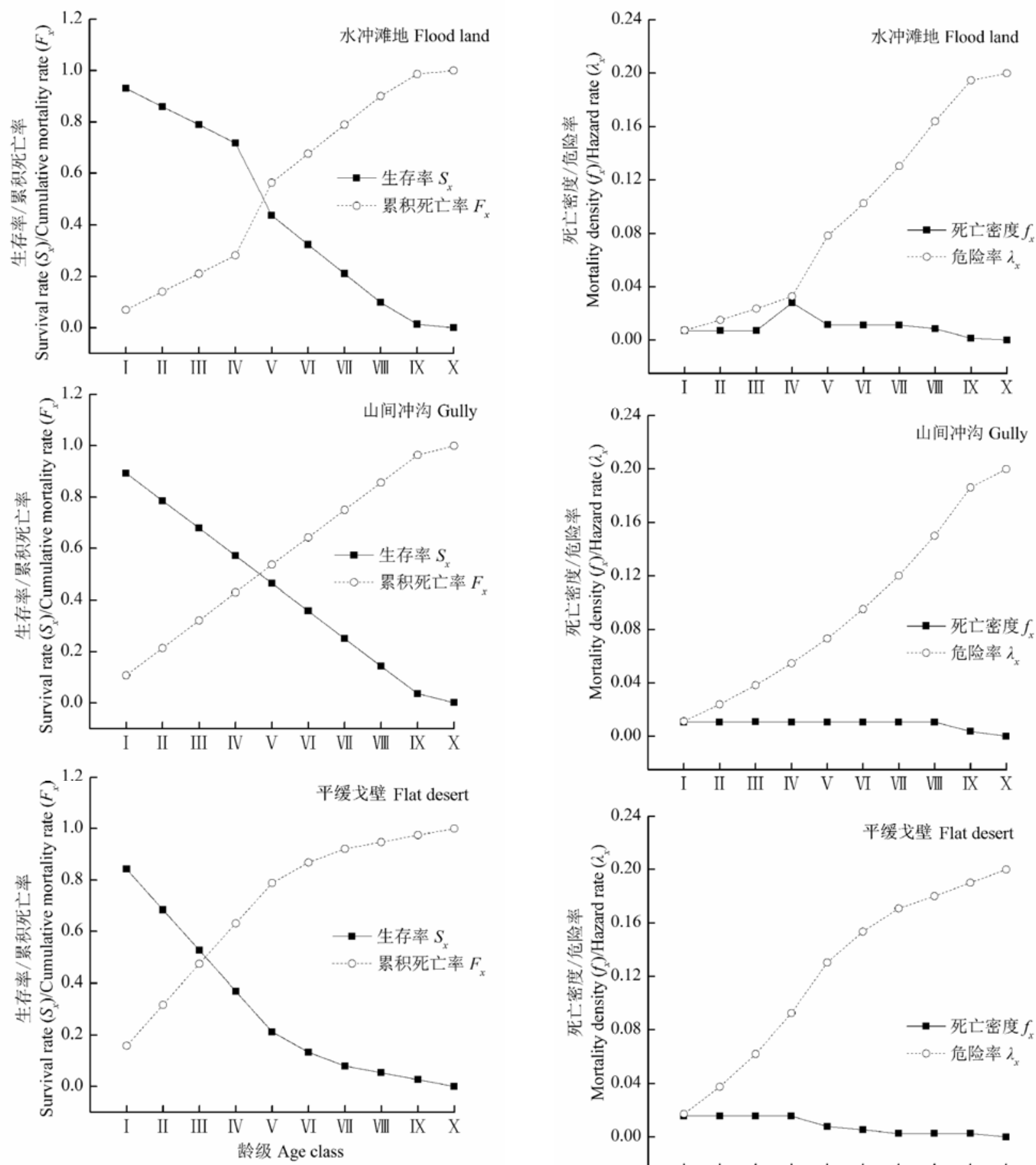

图4 不同生境下裸果木种群生存率和累计死亡率。龄级同 图1。

Fig. 4 Survival rate and cumulative mortality rate of Gymnocarpos przewalskii population in different habitats. Age class see Fig. 1.

曲线均更趋向于Deevey-II型, 说明裸果木种群有相 对稳定的死亡率。同时, 种群数量动态分析也显示 不同生境下的裸果木种群均为增长型。分析其中的 原因, 可能是由于现存IV、V龄级的裸果木个体数

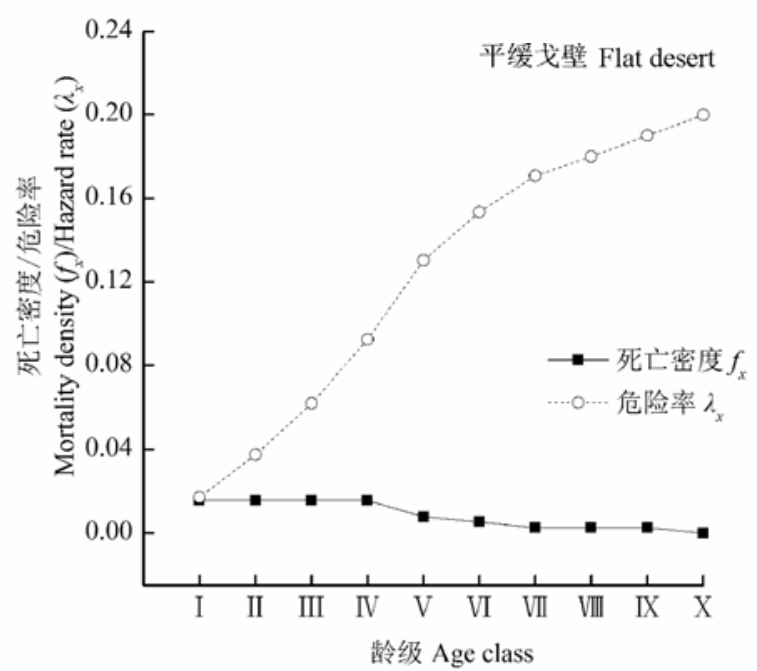

图5 不同生境下裸果木种群死亡密度和危险率。龄级同图1。 Fig. 5 Mortality density and hazard rate of Gymnocarpos przewalskii population in different habitats. Age class see Fig. 1.

量仍然可以在有限的时间内维持后续龄级的更新, 进而保持其种群的稳定性, 这与时间序列预测的结 果一致。然而, 时间序列分析也显示, 由于缺乏幼龄 
表5 不同生境下裸果木种群动态变化的时间序列分析

Table 5 Time sequence analysis of age structure of Gymnocarpos przewalskii population under different habitats

\begin{tabular}{|c|c|c|c|c|c|c|c|c|c|c|c|c|c|c|c|}
\hline \multirow{2}{*}{$\begin{array}{l}\text { 龄级 } \\
\text { Age } \\
\text { class }\end{array}$} & \multicolumn{5}{|c|}{ 水冲滩地 Flood land } & \multicolumn{5}{|c|}{ 山间冲沟 Gully } & \multicolumn{5}{|c|}{ 平缓戈壁 Flat desert } \\
\hline & $\begin{array}{c}\text { 原始数据 } \\
\text { Primary data }\end{array}$ & $M_{2}^{(1)}$ & $M_{4}^{(1)}$ & $M_{6}{ }^{(1)}$ & $M_{8}^{(1)}$ & $\begin{array}{c}\text { 原始数据 } \\
\text { Primary data }\end{array}$ & $M_{2}^{(1)}$ & $M_{4}^{(1)}$ & $M_{6}{ }^{(1)}$ & $M_{8}^{(1)}$ & $\begin{array}{c}\text { 原始数据 } \\
\text { Primary data }\end{array}$ & $M_{2}^{(1)}$ & $M_{4}{ }^{(1)}$ & $M_{6}{ }^{(1)}$ & $M_{8}^{(1)}$ \\
\hline I & 44 & & & & & 16 & & & & & 2 & & & & \\
\hline II & 60 & 52 & & & & 27 & 22 & & & & 5 & 4 & & & \\
\hline III & 67 & 64 & & & & 16 & 22 & & & & 22 & 14 & & & \\
\hline IV & 71 & 69 & 61 & & & 21 & 19 & 20 & & & 35 & 29 & 16 & & \\
\hline $\mathrm{V}$ & 63 & 67 & 65 & & & 30 & 26 & 24 & & & 28 & 32 & 23 & & \\
\hline VI & 43 & 53 & 61 & 58 & & 16 & 23 & 21 & 21 & & 28 & 28 & 28 & 20 & \\
\hline VII & 17 & 30 & 49 & 54 & & 11 & 14 & 20 & 20 & & 8 & 18 & 25 & 21 & \\
\hline VIII & 11 & 14 & 34 & 45 & 47 & 7 & 9 & 16 & 17 & 18 & 2 & 5 & 17 & 21 & 16 \\
\hline IX & 3 & 7 & 19 & 52 & 42 & 1 & 4 & 9 & 14 & 16 & 2 & 2 & 10 & 17 & 16 \\
\hline $\mathrm{X}$ & 3 & 3 & 9 & 23 & 35 & 3 & 2 & 6 & 11 & 13 & 1 & 2 & 3 & 12 & 16 \\
\hline
\end{tabular}

(1), 一次移动平均; $M_{2}, M_{4}, M_{6}, M_{8}$ 分别表示对经历 $2,4,6,8$ 龄级时间后裸果木的种群大小的预测。原始数据为野外的实际调查数据。龄级同图1。

(1), single moving average; $M_{2}, M_{4}, M_{6}, M_{8}$ represent the predicted population size of $G$. przewalskii through 2, 4, 6, 8 age class time, respectively. Primary data represent the field survey data. Age class see Fig. 1.

个体的补充, 3 种生境下IV龄级的个体数量在未来 均会不同程度地下降, 进而导致种群发生衰退。结 合对裸果木种群的生存分析, 进一步说明幼龄个体 的缺乏是其种群衰退的主要原因, 且平缓戈壁生境 中的裸果木种群将先于另外两种生境发生更加快速 的衰退。因此, 人工保护措施的介入是阻止裸果木 种群衰退和进行种群恢复的关键。

\section{3 裸果木种群的保护及恢复对策}

本文分析结果表明: 不同生境下裸果木种群的 结构特征反映出其对水分条件有更高的依赖性。已 有研究表明, 裸果木的有性生殖结实率很低, 在降 水量低于 $45 \mathrm{~mm}$ 的年份甚至不开花, 而无性繁殖分 蓝的幼苗在持续干旱的情况下也很难存活(柴永青 等, 2010)。因此, 在极端干旱的荒漠化环境下仅依 靠降水难以维持其种群的发展。同时, 研究区所属 的疏勒河流域的水资源在利用过程中一直存在重农 业灌溉、轻生态用水的特点(马德海, 2006)。此外, 与 研究区常见的荒漠植物相比, 裸果木叶片中蛋白质 和脂肪含量较高, 营养丰富, 易被食草类动物优先 采食(汪之波和周向军, 2010)。因此, 严格控制放牧 强度、提高自然条件下幼苗的数量是裸果木种群恢 复的关键, 可以在降水充足的年份人工采集裸果木 的种子并散播在水分条件较好的生境内。同时, 应 该进一步重视水资源分配的合理性，促进流域自然 生态系统的可持续发展。

基金项目 国家自然科学基金(31170371)、安西极
旱荒漠国家级自然保护区资源普查项目 (AXBHQ2014-02)。

致谢 感谢安西极旱荒漠国家级自然保护区张星研 究员及其他工作人员为野外调查提供的便利。

\section{参考文献}

Chai YQ, Cao ZZ, Chai ZS (2010). A study on species diversity of a Gymnocarpos przewalskii community in the Subei desert. Acta Prataculturae Sinica, 19(1), 21-27. (in Chinese with English abstract) [柴永青, 曹致中, 蔡卓山 (2010). 肃北地区裸果木荒漠群落构成特征及物种多样 性研究. 草业学报, 19(1), 21-27.]

Chen XD (1999). A study on the method of quantitative analysis for plant population and community structural dynamics. Acta Ecologica Sinica, 18, 214-217. (in Chinese with English abstract) [陈晓德 (1999). 植物种群与群落结构 动态量化分析方法研究. 生态学报, 18, 214-217.]

Deevey ES Jr (1947). Life tables for natural populations of animals. The Quarterly Review of Biology, 22, 283-314.

Gurevitch J, Scheiner SM, Fox GA (2002). The Ecology of Plants. Sinauer Associates, Sunderland, Massachusetts, USA.

Harcombe PA (1987). Tree life tables. Bioscience, 37, 557-568.

Hett JM, Loucks OL (1976). Age structure models of balsam fir and eastern hemlock. The Journal of Ecology, 64, 1029-1044.

Hong W, Wang XG, Wu CZ, He JD, Liao CZ, Cheng Y, Feng L (2004). Life table and spectral analysis of endangered plant Taxus chinensis var. mairei population. Chinese Journal of Applied Ecology, 15, 1109-1112. (in Chinese with English abstract) [洪伟, 王新功, 吴承祯, 何东进, 廖成章, 程显, 封否 (2004). 濒危植物南方红豆杉种群 
生命表及谱分析. 应用生态学报, 15, 1109-1112.]

Jiang H (1992). Population Ecology of Spruce. China Forestry Publishing House, Beijing. (in Chinese) [江洪 (1992). 云 杉种群生态学. 中国林业出版社, 北京.]

Ma DH (2006). Study on water resources development and utilization of Shule River Basin. Water Resources and Hydropower Engineering, 37(4), 1-4. (in Chinese with English abstract) [马德海 (2006). 疏勒河流域水资源开 发利用研究. 水利水电技术, 37(4), 1-4.]

Ma SM, Zhang ML, Sanderson SC (2012). Phylogeography of the rare Gymnocarpos przewalskii (Caryophyllaceae): Indications of multiple glacial refugia in north-western China. Australian Journal of Botany, 60, 20-31.

Ma SM, Zhang ML, Zhang HX, Meng HH, Chen X (2010). Predicting potential geographical distributions and patterns of the relic plant Gymnocarpos przewalskii using maximum entropy and genetic algorithm for rule-set prediction. Chinese Journal of Plant Ecology, 34, 1327-1335. (in Chinese with English abstract) [马松梅, 张明理, 张宏祥, 孟宏虎, 陈曦 (2010). 利用最大熵模型和规则集遗传算 法模型预测子遗植物裸果木的潜在地理分布及格局. 植物生态学报, 34, 1327-1335.]

Ma SM, Zhang ML. (2012). Phylogeography and conservation genetics of the relic Gymnocarpos przewalskii (Caryophyllaceae) restricted to northwestern China. Conservation Genetics, 13, 1531-1541.

Shen SK, Ma HY, Wang YH, Wang BY, Shen GZ (2008). The structure and dynamics of natural population of the endangered plant Euryodendron excelsum H. T. Chang. Acta Ecologica Sinica, 28, 2404-2412. (in Chinese with English abstract) [申仕康, 马海英, 王跃华, 王博轶, 申国 柱 (2008). 濒危植物猪血木(Euryodendron excelsum $\mathrm{H}$. T. Chang) 自然种群结构及动态. 生态学报, 28, 2404-2412.]

Wang W, Liu CR, Ma KP, Yu SL (1999). Population structure and dynamics of Quercus liaotungensis in two broad-leaved deciduous forests in Dongling Mountain, northern China. Acta Botanica Sinica, 41, 425-432. (in Chinese with English abstract) [王巍, 刘灿然, 马克平, 于顺利 (1999). 东灵山两个落叶阔叶林中辽东栋种群 结构和动态. 植物学报, 41, 425-432.]

Wang ZB, Zhou XJ (2010). Research progress on rare endangered plant Gymnocarpos przewalskii. Resource Development \& Market, 26, 436-437, 446. (in Chinese with English abstract) [汪之波, 周向军 (2010). 珍稀濒危植 物裸果木研究进展. 资源开发与市场, 26, 436-437, 446.]

Wu CZ, Hong W, Xie JS, Wu JL (2000). Life table analysis of Tsuga longibracteata population. Chinese Journal of Applied Ecology, 11, 333-336. (in Chinese with English abstract) [吴承祯，洪伟，谢金寿，吴继林 (2000). 珍稀 濒危植物长苞铁杉种群生命表分析. 应用生态学报, 11 , 333-336.]

Xiao YA, He P, Li XH, Deng HP (2004). Study on numeric dynamics of natural populations of the endangered species Disanthus cercidifolius var. longipes. Acta Phytoecologica Sinica, 28, 252-257. (in Chinese with English abstract) [肖 宜安, 何平, 李晓红, 邓洪平 (2004). 濒危植物长柄双 花木自然种群数量动态. 植物生态学报, 28, 252-257.]

Xie TT, Su PX, Zhou ZJ, Zhang HN, Li SJ (2014). Structure and dynamic characteristics of Calligonum mongolicum population in the desert-oasis ecotone. Acta Ecologica Sinica, 34, 4272-4279. (in Chinese with English abstract) [解婷婷, 苏培秃, 周紫鹃, 张海娜, 李善家 (2014). 荒 漠绿洲过渡带沙拐菄种群结构及动态特征. 生态学报, 34, 4272-4279.]

Xie ZQ, Chen WL, Lu P, Hu D (1999). The demography and age structure of the endangered plant population of $\mathrm{Ca}$ thaya argyrophylla. Acta Ecologica Sinica, 19, 523-528. (in Chinese with English abstract) [谢宗强, 陈伟烈, 路 鹏, 胡东 (1999). 濒危植物银杉的种群统计与年龄结 构. 生态学报, 19, 523-528.]

Yang FX, Wang SQ, Xu HG, Li BQ (1991). The theory of survival analysis and its application to life table. Acta Ecologica Sinica, 11, 153-158. (in Chinese with English abstract) [杨风翔, 王顺庆, 徐海根, 李邦庆 (1991). 生 存分析理论及其在研究生命表中的应用. 生态学报, 11 , 153-158.]

Yang JM, Chen XL, Gong DJ (2013). Study on species diversity of rare endangered plant Gymnocarpos przewalskii communities. Journal of Anhui Agricultural Sciences, 41, 8508-8511. (in Chinese with English abstract) [杨建美, 陈学林, 龚大洁 (2013). 珍稀濒危植物裸果木群落物种 多样性研究. 安徽农业科学, 41, 8508-8511.]

Yi XM, Zhang Y, Ji LZ (2013). Population structure of Phellodendron amurense in Changbai Mountains of northeast China. Chinese Journal of Ecology, 32, 2257-2262. [易雪 梅, 张悦, 姬兰柱 (2013). 长白山黄檗种群结构. 生态 学杂志, 32, 2257-2262.]

Zheng GZ, Yue LP, He JF, Wang JX, Zhang YL (2006). Grain-size characteristics of the sediments at Palaeoswamp in Anxi County in downstream of Shulehe River during Holocene and its paleoclimatic significance. Acta Sedimentologica Sinica, 24, 733-739. (in Chinese with English abstract) [郑国璋, 岳乐平, 何军锋, 王建新, 张玉玲 (2006). 疏勒河下游安西古沼泽全新世沉积物粒度特征 及其古气候环境意义. 沉积学报, 24, 733-739.]

责任编委: 李镇清 责任编辑: 李 敏 